\title{
Effect of Temperature on The Electron Concentration of Crystalline GaAs Semiconductor Based on The p-n Junction Due to Deformation Potential Scattering
}

\author{
Nova Alviati ${ }^{1}$, Samsiatun Hoiriyah ${ }^{1}$, Misto ${ }^{1}$ and Edy Supriyanto ${ }^{1}$ \\ ${ }^{1}$ Department of Physics, Faculty of Mathematics and Natural Sciences, University of Jember, \\ Jalan Kalimantan No. 37, Jember 68121, Indonesia \\ anovaalviati11@gmail.com
}

\begin{abstract}
The electrical characteristics of semiconductor materials can be predicted based on the transport of charge carriers within the material. Under room temperature, the electrical properties of semiconductor materials can be exploited by knowing the value of their electron mobility to predict the number of electrons that experience the transport mechanism. When the material is observed under room temperature, the interaction of electrons and the lattice atoms' vibrations result in deformation potential scattering. This can stimulate electron mobility changes, which can affect the number of free electrons in semiconductor materials. The research results presented in this paper simulate the number of electrons that change due to electrons' mobility in the GaAs crystal. This material undergoes potential scattering deformation due to the interaction between electrons and phonons at temperature $(40-100) \mathrm{K}$. The simulation is carried out by modeling the GaAs semiconductor material in the form of a $p-n$ junction. The temperature variation given to the material shows a significant change in concentration in the junction area. In contrast, in the contact area's vicinity with the external circuit, both the $\mathrm{p}$-layer and the $\mathrm{n}$-layer show relatively constant electron concentrations.
\end{abstract}

Keywords: Deformation Potential Scattering, Electron Concentration, GaAs, Simulation, Electron Mobility

\section{Introduction}

GaAs semiconductor crystal is an alloy semiconductor material composed of Gallium (Ga) and Arsenic (As). At room temperature, this material has an energy band gap of $1.43 \mathrm{eV}$ with a direct bandgap energy band structure [1]. This energy band gap is more expansive than $\mathrm{Si}$, so this material is better for the manufacture of electronic devices that can operate up to highfrequency regions [2].

In general, all electronic devices are designed to operate at room temperature (300K). Theoretically, above a temperature of $0 \mathrm{~K}$, the atoms of semiconductor materials experience lattice vibrations that interfere with electrons' free movement in the material. The interaction between electrons and vibrating lattice atoms gives rise to a scattering phenomenon in a semiconductor known as phonon/lattice scattering [3].

One type of phonon scattering that occurs in GaAs semiconductor crystal material is deformation potential scattering. The deformation potential scattering event causes periodic changes in the distance between lattice points on the atoms of the crystal [4]. The dependence of electron mobility on temperature due to the deformation potential scattering effect is mathematically expressed by the following equation [5]: 
$\mu_{n} \approx T^{-3 / 2}$

The parameter $\mu_{\mathrm{n}}$ is the mobility of the electron, and T is the temperature. This scattering phenomenon can affect the distribution of electron concentrations in the material. Therefore, it is necessary to conduct research studies to find out how much influence is generated. The study can explain the GaAs semiconductor material's electrical characteristics, mainly due to the deformation potential scattering. Furthermore, the value of the electron concentration obtained is plotted according to temperature variations so that the $\mathrm{n}-\mathrm{T}$ characteristic curve is obtained due to the deformation potential scattering event.

\section{Materials and Methods}

This research was conducted by applying the finite element method. GaAs semiconductor crystal material is modeled into 2-dimensional cross-sections and divides the area into small triangular elements with the non-linear distribution of electric fields and charge carriers. The partial differential equation of the GaAs semiconductor is applied to the geometry by applying several material boundary conditions. Each element's solution is the concentration of electrons as free charge carriers in the device being modeled.

The calculation of electron concentration due to the deformation potential scattering phenomenon was carried out at $40 \mathrm{~K}, 60 \mathrm{~K}, 80 \mathrm{~K}$, and $100 \mathrm{~K}$. The input of the value of electron mobility for each temperature was $\left(3 \times 10^{14} \mu \mathrm{m}^{2} / \mathrm{Vs}\right),\left(1.5 \times 10^{14} \mu \mathrm{m}^{2} / \mathrm{Vs}\right),\left(9 \times 10^{13} \mu \mathrm{m}^{2} / \mathrm{Vs}\right)$ and $\left(7 \times 10^{13} \mu \mathrm{m}^{2} / \mathrm{Vs}\right)$. As control data, simulations were carried out at a temperature of $300 \mathrm{~K}$ with an electron mobility value of $\left(8500 \times 10^{8}\right) \mu \mathrm{m}^{2} / \mathrm{Vs}$. Stages of the simulation process carried out from entering the input data; include GaAs semiconductor crystal geometry (Figure 1), GaAs semiconductor crystal parameters [6,7], and boundary condition setting [8], which was applied to the fourth boundaries in Figure 1. Positions 2 and 3 are the boundary lines between the device and metal contacts. Here, the Dirichlet conditions are imposed at the metalsemiconductor surfaces. Otherwise, the Neumann condition have applied for positions 1 and 4 , we have applied Neumann condition as the boundary condition. The final simulation process was to solve the Poisson and Continuity equations of the electrons. 


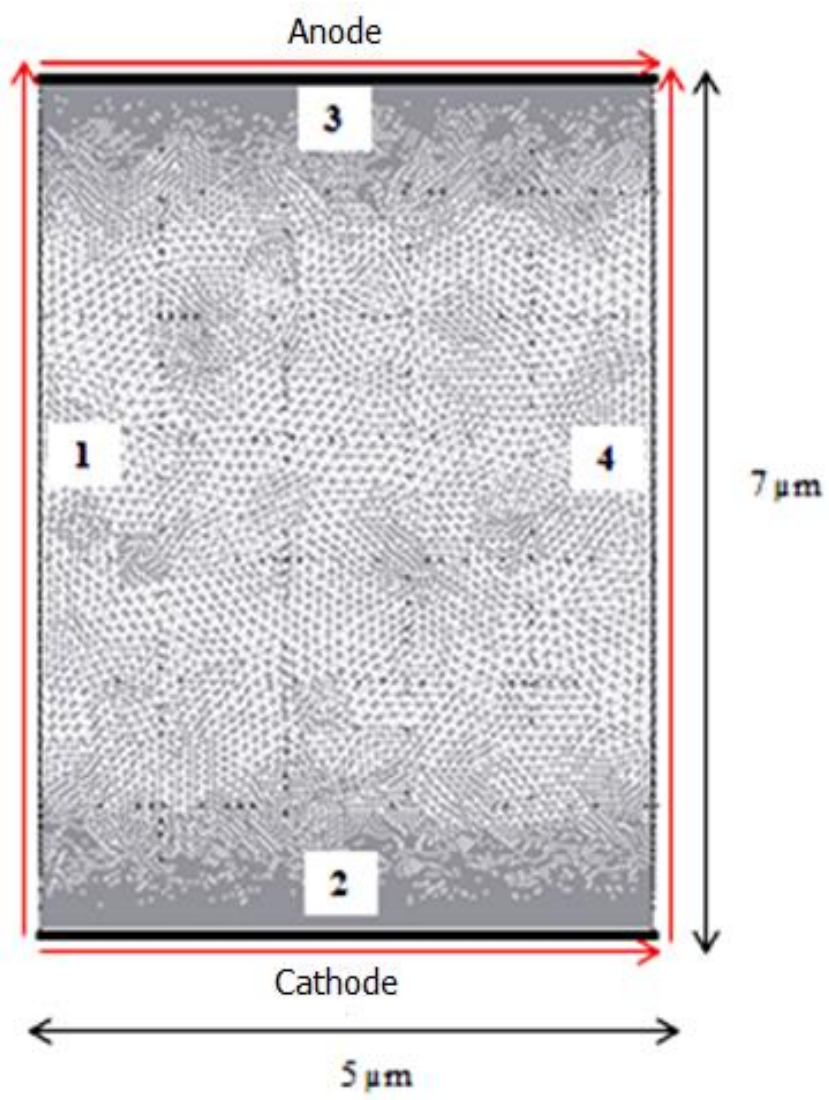

Figure 1. GaAs semiconductor crystal geometry which has been divided into triangular-shaped elements

The results obtained from the simulation process are the distribution of electron concentrations in all areas of the device being modeled. The electron concentrations at several observation points are analyzed. The observation areas include: anode area $A(0.0725 ;-0.00629)$, the area near anode $B(0.26 ;-0.2)$, the $p$ layer area near the joint, namely point $C(0.0642 ;-0.326)$ and $D$ $(0.366 ;-0.345)$, the $n$ layer area near the joint, namely $E(0.155 ;-0.357)$ and $F(0.366 ;-0.37)$, the area near the cathode $G(0.26 ;-0.502)$ and cathode area $H(0.366 ;-0.694)$. The temperature variations were applied to the device model, and the effect on the concentration of electrons in the material had been analyzed.

\section{Results and Discussion}

\section{Electron Concentration Distribution in Deformation Potential Scattering Phenomenon in GaAs Semiconductor Crystal}

The results of modeling the GaAs semiconductor crystal material from this study describe a 2dimensional profile of the electron concentration distribution and the number of electron concentrations in the material. The distribution of electrons in the $p-n$ junction device is visually shown in Figure 2, while the number of electron concentrations can be seen in Table 1. 
Table 1. Electron concentration at $T=40 \mathrm{~K}$ and $\mu_{\mathrm{n}}=\left(3 \times 10^{14}\right) \frac{\mu \mathrm{m}^{2}}{\mathrm{Vs}}$

\begin{tabular}{ccc}
\hline Position & Coordinate & $\begin{array}{c}\text { Electron concentration } \\
\left(\mu \mathrm{m}^{-1}\right)\end{array}$ \\
\hline A & $(0.07250 ;-0.00629)$ & $1.326 \times 10^{2}$ \\
B & $(0.26000 ;-0.20000)$ & $1.649 \times 10^{2}$ \\
C & $(0.06420 ;-0.32600)$ & $2.510 \times 10^{7}$ \\
D & $(0.36600 ;-0.34500)$ & $6.758 \times 10^{8}$ \\
E & $(0.15500 ;-0.35700)$ & $11.879 \times 10^{11}$ \\
F & $(0.36600 ;-0.37000)$ & $15.096 \times 10^{14}$ \\
G & $(0.26000 ;-0.50200)$ & $16.264 \times 10^{16}$ \\
H & $(0.36600 ;-0.69400)$ & $16.582 \times 10^{16}$ \\
\hline
\end{tabular}

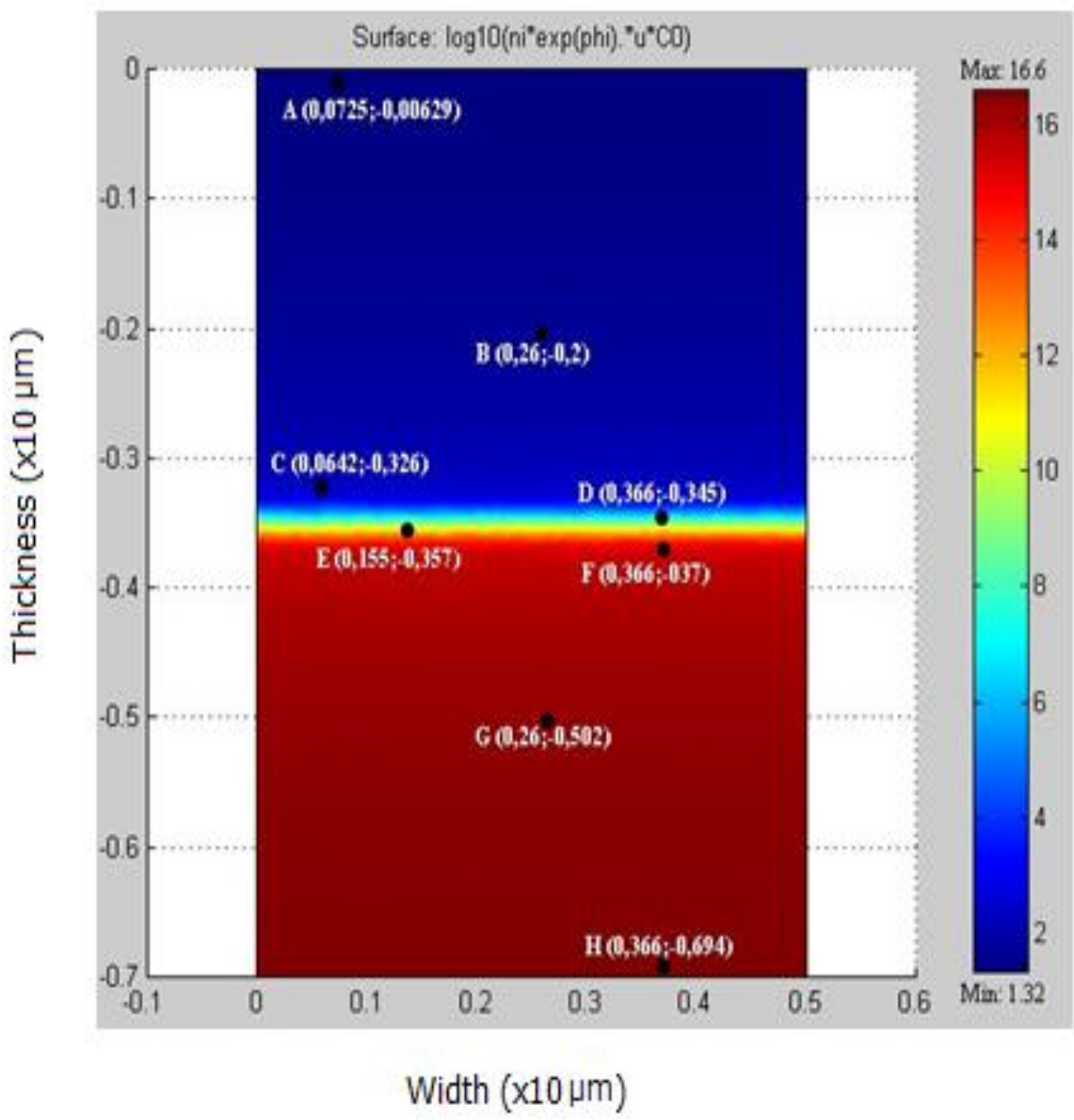

Figure 2. Modeling results of electron concentration distribution at $\mathrm{T}=40 \mathrm{~K}$ in the event of potential deformation scattering with each color on the right side representing the scale of the electron concentration value, which is 10 to the power of numbers each color index 
Figure 2 shows that the amount of electron concentration at a $40 \mathrm{~K}$ temperature depends on each color that appears. Each color represents a scale, which is the power index of the number 10. At point $A$, the concentration of electrons has the order $10^{2} \mu \mathrm{m}^{-1}$. Number 2 in the upper index of number 10 is represented in blue. At temperatures of $60 \mathrm{~K}, 80 \mathrm{~K}$ and $100 \mathrm{~K}$, the simulation results show a similar image to the state at $40 \mathrm{~K}$. However, numerically, the electron concentration at each point of the observation area is not the same for these temperature variations. The simulation results show that the closer to the cathode (negative pole), the greater the electrons' number, which is indicated by the higher electron concentration. These results are consistent with the theory that the highest number of electrons is in the negative pole [9].

The simulation results of the GaAs semiconductor crystal material shown in Figure 2 provide information on the presence of two dominant colors in the material, separated from each other. The color contrast of the two is quite large, which means a difference in the amount of concentration in the two areas. Dark red represents the maximum electron concentration scale, and dark blue represents the minimum electron concentration scale. These results can be analyzed based on the types of atomic bonds in the GaAs semiconductor crystal material, a 2element semiconductor alloy whose atomic bonds consist of mostly covalent bonds and a small portion of ionic bonds [10]. The character of ionic bonds in the material causes the oscillation of ions in the GaAs semiconductor crystal material when given a temperature so that a dipole moment is formed per volume unit, which is called polarization [11]. The polarization event causes a difference in the concentration of electrons in the geometry of the material so that there is a part of the geometry that has a maximum electron concentration (dark red) and a part of the geometry that has a minimum electron concentration (dark blue).

The contrasting color difference based on the electron concentration value between the two regions in the GaAs material causes the formation of a central region that limits the two dominant regions in the material's geometry. The middle area in the geometry of the material is almost similar to the depletion region in the $p-n$ diode junction, which is analyzed as the separation region between positive atoms (low electron concentration) and negative atoms (high electron concentration) in GaAs semiconductor crystal material which has ionic bond characteristics [10].

At all temperatures, namely $40 \mathrm{~K}, 60 \mathrm{~K}, 80 \mathrm{~K}$ and $100 \mathrm{~K}$, there was a change in the width of the central region of the GaAs semiconductor crystal geometry (similar to the depletion area), namely the widths respectively at the temperature variation of $0.44 \mu \mathrm{m}, 0.46 \mu \mathrm{m}, 0.48 \mu \mathrm{m}$ and $0.5 \mu \mathrm{m}$, namely at the position of region $\mathrm{C}$ to region $\mathrm{F}$. The change in the middle area (region $\mathrm{C}$ to region $\mathrm{F}$ ) is relatively small, with a range of $0.02 \mu \mathrm{m}$ at any given temperature variation. This occur because, at shallow temperatures $(<200 \mathrm{~K})$, the lattice vibration energy of the crystal is not sufficient to ionize all electrons in the material, so that the change in the value of the electron concentration is not too large, which is indicated by a relatively small change in the width of the color area [13]. However, the event being studied is the deformation potential scattering, which is focused on the phenomenon of electron-phonon interaction so that what is reviewed is the scattering effect that occurs in the material. Increasing the temperature above OK triggers lattice vibrations, causing the scattering in the material to intensify, affecting the flow of electrons from the cathode to the anode (electron diffusion current). Therefore, based on the numerical results, it is informed that simultaneously when the temperature in the material increases, the value of the electron concentration in the $E$ and $F$ regions decreases while the electron concentration 
values in the $C$ and $D$ regions increase, thus indicating the occurrence of electron diffusion currents in regions the material.

The simulation of the distribution of electron concentration values at $300 \mathrm{~K}$ (room temperature) was carried out as a control value in this study. This is understandable because the temperature of $300 \mathrm{~K}$ is the operating temperature of the semiconductor material; most electronic devices are designed to operate at this temperature. In general, the analysis is understood qualitatively in the semiconductor material that the value of the electron concentration in the semiconductor material will increase along with the increase in the value of temperature given to the material [12]. For this reason, the simulation results at a temperature of $300 \mathrm{~K}$ are used as the benchmark value of the simulation results that have been carried out at temperatures of $40 \mathrm{~K}$, $60 \mathrm{~K}, 80 \mathrm{~K}$ and $100 \mathrm{~K}$. At this temperature, there is a change in the width of the central part of the geometry (regions $\mathrm{C}$ to where $\mathrm{F}$ ) is $0.66 \mu \mathrm{m}$ in width. By the theory that if the temperature (> $200 \mathrm{~K}$ ), then the lattice vibrational energy is sufficient to ionize all electrons in the semiconductor material [13]. This results in the dark red area (region $\mathrm{G}$ and region $\mathrm{H}$ ) getting narrower, which indicates an electron diffusion current. This phenomenon indicates that the electrons in these regions have ionized and flowed towards the areas above them (region $D$ and region $E$ ). However, an increase in temperature also increases the number of electrons so that electrons' mobility is reduced, which is measured from the smaller electron mobility parameter. This causes the movement of electrons to become slower as the temperature in the material increases. This slower movement of electrons disrupts the process of electron diffusion towards the anode, as a result of which the electrons gather in the central region of the geometry of the material (region $\mathrm{C}$, region $\mathrm{D}$, region $\mathrm{E}$, and region $\mathrm{F}$ ). Therefore, at a temperature of $300 \mathrm{~K}$, the increase in the width of the central area of the GaAs semiconductor crystal geometry is more significant than the previous temperatures because more electrons are ionized from the material.

\section{Characteristics Curve of $\mathrm{n}-\mathrm{T}$ GaAs Semiconductor Crystals Due to Temperature Variations in Deformation Potential Scattering Process}

The change in the value of the electron concentration due to the increase in temperature applied to the GaAs semiconductor crystal material causes different effects in each region in the material model's geometry. For this reason, the $n-T$ characteristic curve is made so that the examination of the relationship between the electron concentration value and temperature can be easier to see and analyze. The results of the $n-T$ characteristic curve in the deformation potential scattering are shown in Figure 3. The characteristic n-T curves shown in Figure 3 and Figure 4 represent the change of electron number for all regions in the GaAs semiconductor crystal material geometry.

In special case, the electron concentration at position $\mathrm{A}$ of Figure $3 \mathrm{a}$ (close to anode) and $\mathrm{H}$ of Figure $4 \mathrm{~b}$ (close to cathode), the result peformed that the increasing temperature from $20 \mathrm{~K}$ to $100 \mathrm{~K}$ did not alter the number of the electron concentration. Therefore, the pattern of the $\mathrm{n}-\mathrm{T}$ characteristic curve is constant. This is because the temperature given is relatively low while the voltage is constant so that in this region, a quasi-neutral state occurs with an indication of the number of electrons being fixed. 


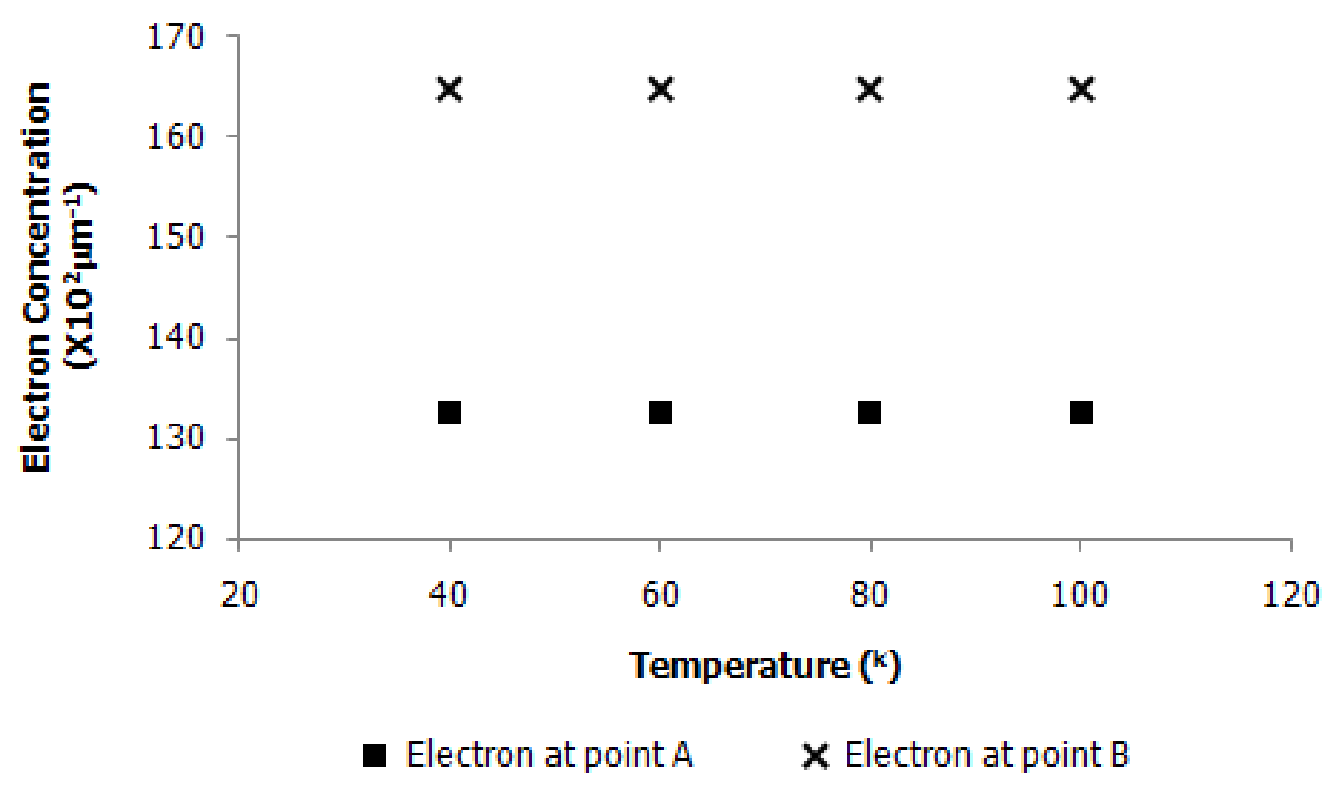

(a)

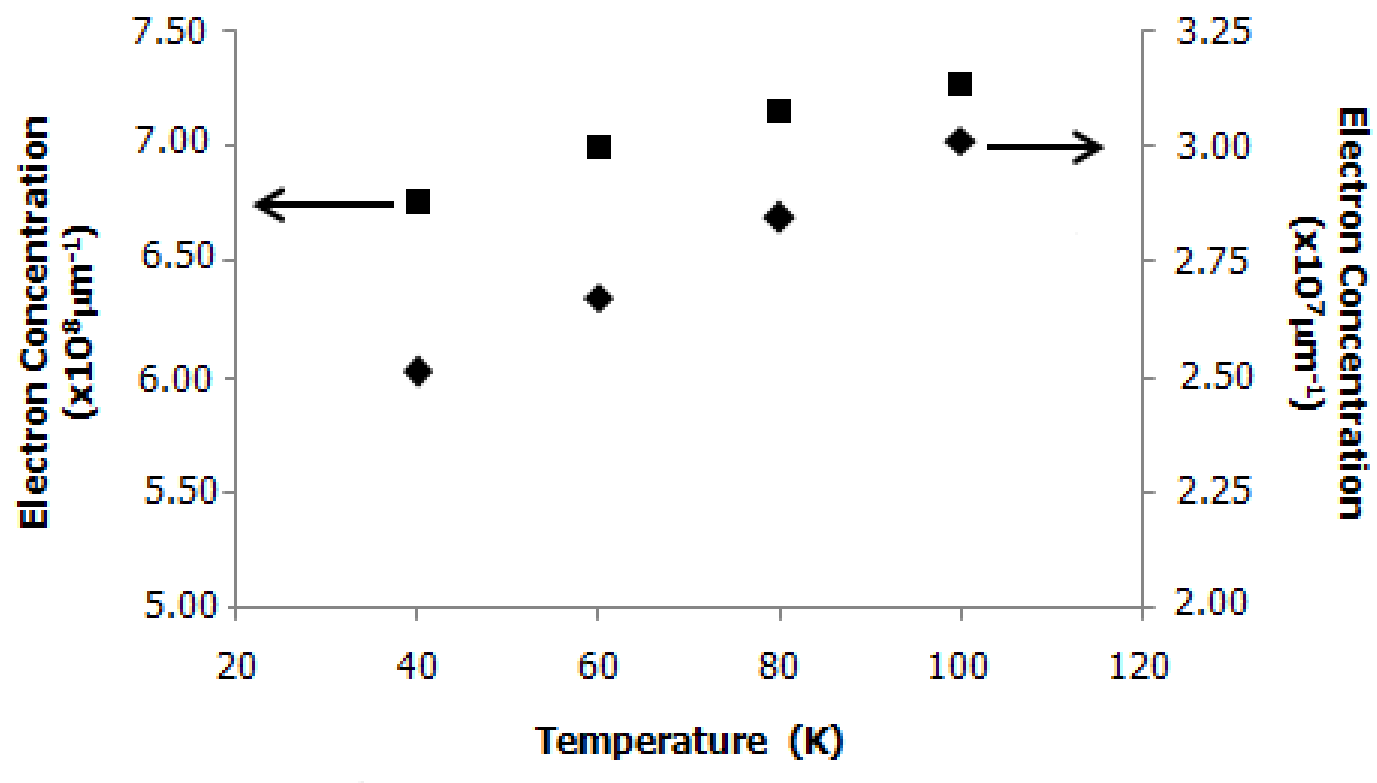

Electron at point C Electron at point $D$

(b)

Figure 3. The curve of electron concentration as function of temperature at point $A$, and $B(a)$ and also for point $C$, and $D(b)$ 


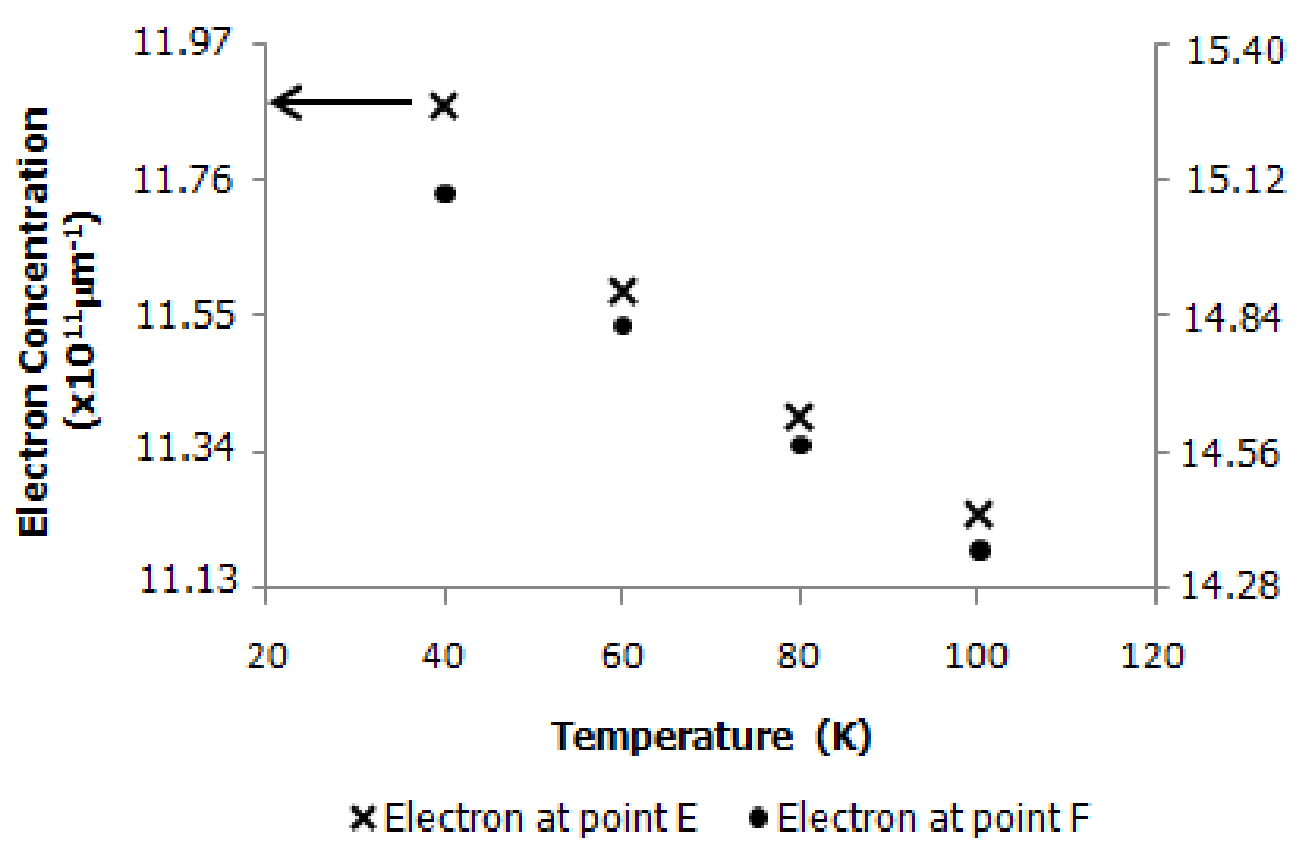

(c)

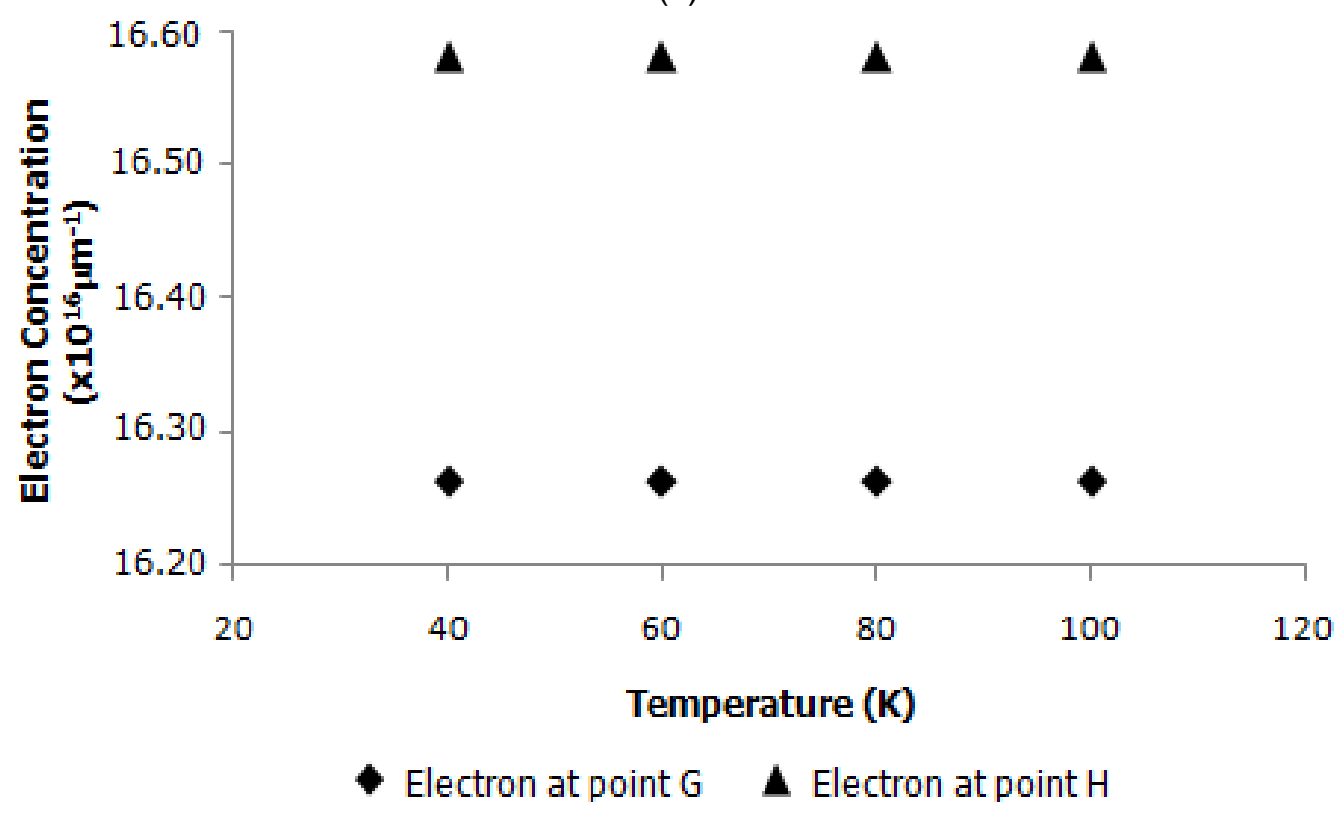

(d)

Figure 4.The curve of electron concentration as function of temperature at point $E$, and $F(a)$ and also for point $G$, and $H(b)$

Furthermore, for the central region (point $C$ and $D$ ), the result performed that the greater the temperature applied to the GaAs semiconductor crystal, the greater the value of the electron concentration obtained. There is an increase in the number of electron concentration from $C$ to $\mathrm{D}$ point. Conversely, in the $\mathrm{E}$ region, there is a tendency that increasing the temperature given to the material, the value of the electron concentration decreases. This result is opposite to the 
$D$ region. This phenomenon occurs due to an electron diffusion current so that the electrons tend to flow from the $E$ region to the $D$ region. The value of the electron concentration in the $E$ region have also decreased with increasing temperature.

\section{Conclusions}

Based on the discussion results, the simulation results in the phenomenon of deformation potential scattering for all temperature variations given to the GaAs semiconductor crystal represent different electron concentration. The closer to the cathode, the greater the value of the electron concentration. Furthermore, the central region of the material's geometry, similar to the depletion region, tends to have a different area width when given temperature variations. Increasing the temperature from $40 \mathrm{~K}$ to $100 \mathrm{~K}$ resulted in a change in the width of the depletionlike area of $0.06 \mu \mathrm{m}$. The number of electron concentration around the middle area perform significant change due to the increasing of temperature. A constant state occurs in the anode region, near the anode, cathode and near the cathode.

\section{References}

[1] L Fuller, 2001, Gallium Arsenide Device, Technologies \& Integrated Circuits, http://people.rit.edu/ Iffeee/gaas.pdf.

[2] Sutrisno, 1986, Elektronika I Teori Dasar dan Penerapannya, Institut Teknologi Bandung, Bandung, Indonesia.

[3] A Subekti, 2003, Diktat Kuliah Semikonduktor, FMIPA Universitas Jember, Jember, Indonesia.

[4] K Seeger, 1989, Semiconductor Physics an Introduction, Springer-Verlag, USA.

[5] S J Manion, 1988, Acoustic Phonon Scattering in Modulation Doped Aluminumx Gallium1xArsenide / Gallium Arsenide Heterojunctions, ADA 198 512, Thesis, University of Illinois, Urbana-Champaign.

[6] S Singhal, A K Saxena, and S Dasgupta, 2007, Estimation Of Various Scattering Parameters and 2-DEG Mobilities From Electron Mobility Calculations in The Three Conduction Bands $\Gamma$, $L$ dan $X$ of Gallium Arsenida, PRAMANA-Journal of Physics: Indian Academy of Sciences, Volume 69, page 687-692.

[7] D Rusdiana, L Hasanah, and E Suhendi, 2010, Mekanisme Hamburan Defek Statis Dan Vibrasi Termal Terhadap Mobilitas Elektron Pada Film Tipis GaN, Berkala Fisika ISSN: 14109662, Volume 13 No. 1, page 39-44.

[8] Alviati, N. 2015. Simulasi Distribusi Konsentrasi Elektron Kristal Semikonduktor Gaas Pada Peristiwa Deformation Potential Scattering Berbasis Metode Elemen Hingga. Skripsi, Universitas Jember. Jember.

[9] F H Mitchell, 1959, Fundamentals Of Electronics. London: Addison-Wesley Publishing Company, Inc.

[10]M Fukuda, 1999, Optical Semiconductor Devices, Canada: John Wiley \& Sons, Inc.

[11]K Seeger, 1989, Semiconductor Physics An Introduction, USA : Springer-Verlag. 
Submitted : February 1, 2019

Accepted : March 28, 2019

Online : Mei 2, 2019

doi : 10.19184/cerimre.v2i1.20560

[12]R K Puri and V K Babbar, 2001, Solid State Physics \& Electronics, New Delhi: S. Chand \& Company LTD.

[13]A Subekti, 2001, Semikonduktor (Tipe, Energi Gap dan Statistik), FMIPA Universitas Jember, Jember, Indonesia. 